\title{
Hypothalamic Thyroid Hormone in Energy Balance Regulation
}

\author{
Annika Herwig Alexander W. Ross Kanishka N. Nilaweera Peter J. Morgan Perry Barrett
}

Molecular Endocrinology Group, Rowett Research Institute and Aberdeen Centre for Energy Regulation and Obesity, Bucksburn, Aberdeen AB21 9SB, UK

\section{Key Words}

Thyroid hormone · Energy balance - Hypothalamus . Arcuate nucleus · Deiodinases

\section{Summary}

Thyroid hormone has been known for decades as a hormone with profound effects on energy expenditure and ability to control weight. The regulation of energy expenditure by thyroid hormone primarily occurs via regulation of the activity, or expression, of uncoupling proteins in peripheral tissues. However, mechanistically this requires a signal from the brain to change circulating levels of thyroxine and thyroid hormone or increased sympathetic drive to peripheral tissues to alter local thyroid hormone levels via increased expression of type 2 deiodinase. However, little consideration has been given to the potential role and involvement of thyroid hormones action in the brain in the regulation of energy balance. Recent evidence implicates thyroid hormone as a shortterm signal of energy deficit imposed by starvation. Furthermore, thyroid hormone action within the hypothalamus is involved in adjusting long-term energy expenditure in seasonal animals which endure food shortages in winter. Evidence from several studies suggests that regulation of type 2 and type 3 deiodinase enzymes in tanycytes of the third ventricle are gatekeepers of thyroid hormone levels in the hypothalamus. This paper reviews some of the evidence for the role of deiodinase enzymes and the actions of thyroid hormone in the hypothalamus in the regulation of energy balance.

\section{Reassessing an 'Old' Candidate in Energy Balance Regulation - Thyroid Hormone}

Since the discovery of leptin our understanding of central mechanisms in the brain governing appetite and energy expenditure has increased markedly. This includes the cross-talk between the brain and periphery in order to maintain the optimal balance of metabolisable fuels to meet physiological requirements. The identification of many of the key hormones and neuropeptides involved in appetite and energy balance regulation, such as neuropeptide Y (NPY), leptin and melanocortin, has occurred only relatively recently. Nevertheless long before the discovery of these neuropeptides and hormones, thyroid hormone was known to alter metabolic rate [1, 2] and has been used in various forms to reduce weight since the 1940s [3]. Despite the fact that thyroid hormone was one of the earliest known hormones to affect body weight, little is known about how thyroid hormone acts in the brain to regulate appetite and energy expenditure.

The role of thyroid hormone in the regulation of body weight is best illustrated in patients with thyroid dysfunction resulting in conditions of hypothyroidism or hyperthyroidism. In patients with hypothyroidism, individual body weight can be increased by as much as $30 \%$ relative to the euthyroid state. On the other hand, hyperthyroidism can lead to decreased body weight by up to $15 \%$. Although much of the weight loss or gain can be attributed to the role of thyroid hormones in affecting metabolic rate, a percentage in each group do not respond to the establishment of the euthyroid state. This may be indicative of additional roles or mechanisms for thyroid hormones in regulating appetite and energy expenditure [3-5].

\begin{tabular}{ll}
\hline KARGER & @ 2008 S. Karger GmbH, Freiburg \\
Fax +49 7614520714 & Accessible online at: \\
$\begin{array}{l}\text { E-mail Information@Karger.de } \\
\text { www.karger.com }\end{array}$ & www.karger.com/ofa
\end{tabular}


Fig. 1. The hypothalamo-pituitary-thyroid axis and feedback mechanisms.

A Thyroid hormone production is controlled by thyrotropin-releasing hormone (TRH) produced by cell groups of the paraventricular nucleus (PVN) of the hypothalamus. The TRH neurons project to the median eminence where TRH crosses the fenestrated capillaries of the portal system for direct transport to the anterior pituitary gland. Here TRH induces secretion of thyroid stimulating hormone (TSH). TSH is released in the blood stream and stimulates thyroid hormone production in the thyroid gland. The thyroid gland releases thyroxine (T4), the dominant form of thyroid hormone in the circulation, which is converted to the bioactive form $\mathrm{T} 3$ by deiodinase enzymes (see fig. 2) in a tissue specific manner. B Thyroid hormones (T3/T4) that travel in the blood can re-enter the hypothalamus and feed back on the PVN and TRH production. T4 enters the brain via the blood-brain barrier as well as through the cerebrospinal fluid. It is transported via tanycytes lining the third ventricle (3V) and astrocytes (Ast) in median eminence and arcuate nucleus. Expression of type 2 deiodinase in these cells converts T4 to bioactive T3. Transported to the arcuate nucleus it can stimulate the activity of neuropeptide Y (NPY)/agouti-related protein (AgRP) neurons which in turn inhibit TRH production and increase appetite. Under fasting conditions this mechanism promotes increased feeding activity together with decreased peripheral energy expenditure. AgRP blocks the anorexigenic effect of $\alpha$-melanocyte-stimulating hormone ( $\alpha$-MSH) from pro-opiomelanocortin (POMC) / cocaine-amphetamine-regulated transcript (CART) neurons, the second important cell group in the arcuate nucleus. When activated $\alpha$-MSH decreases food intake stimulates TRH neurons to increase TRH production, consequently rising thyroid hormone levels to raise peripheral energy expenditure. T3 might also act elsewhere in the hypothalamus such as VMN. Such interactions may form an integrated network involving thyroid hormone to regulate food intake and energy expenditure.

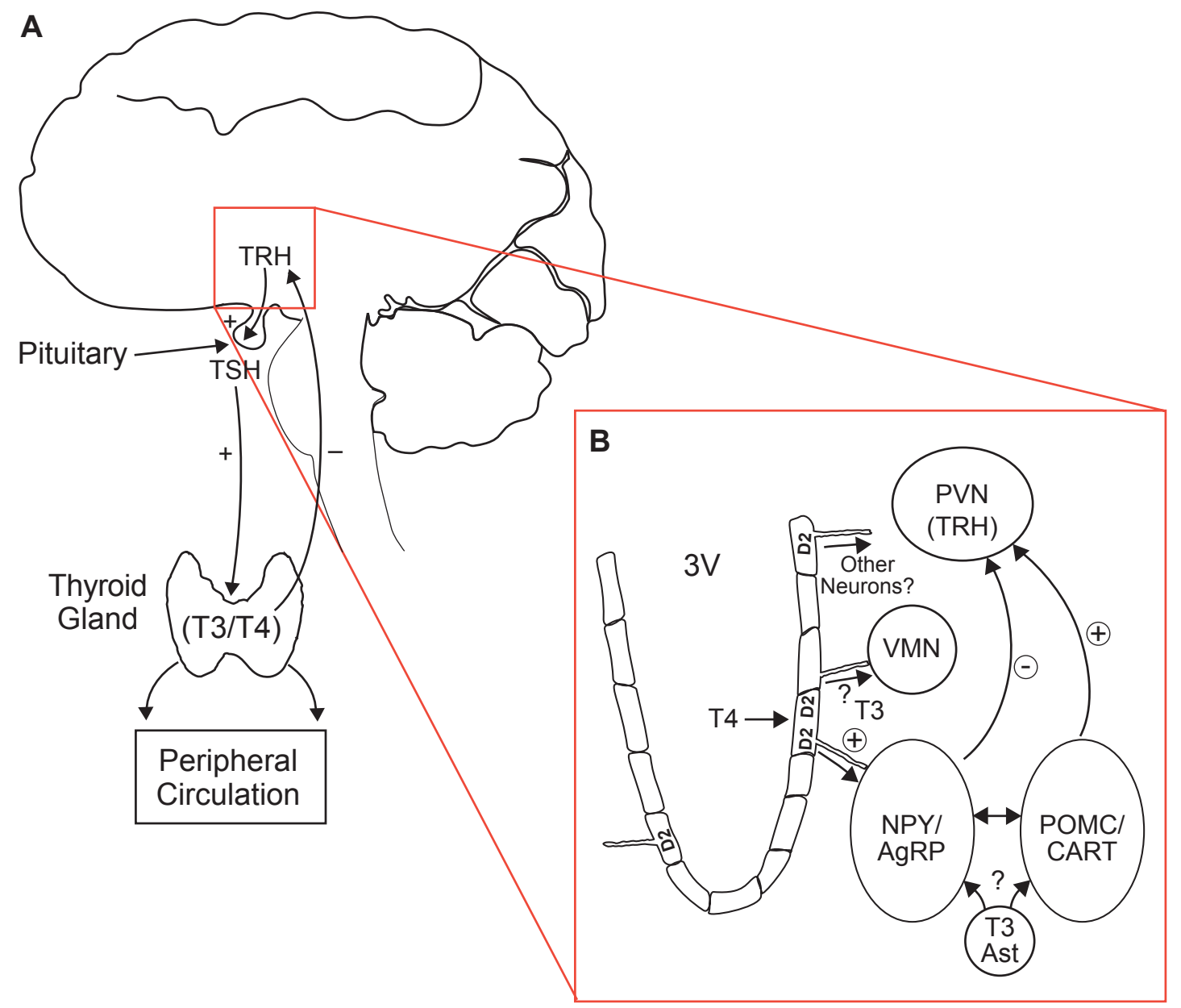

\section{Adaptive Thermogenesis - Thyroid Hormone Regulated Energy Expenditure in the Periphery}

The role of thyroid hormones in thermogenic responses resulting in energy expenditure has been reviewed elsewhere [6-8], but for an overall picture of thyroid hormones in appetite and energy balance, a brief outline is given here.

During the process of generating ATP by oxidative phosphorylation through the Krebs cycle, a proton gradient is established across the inner mitochondrial membrane. However, a proportion of the proton gradient leaks through uncoupling proteins, which leads to the generation of heat. Although, essentially a by-product of aerobic respiration, heat generated in this way maintains an environment for proper functioning of biochemical processes. The minimum energy required to enable body metabolism at rest is known as the basal metabolic rate and the heat produced as a consequence of the basal metabolic rate termed obligatory thermogenesis.

Additional heat production is generated as result of eating a meal or a drop in ambient temperature below thermoneutral. These challenges to energy balance increase sympathetic drive to the periphery, where in selected tissues, such as brown adipose tissue in rodents or muscle in either rodents or humans, it leads to increased heat production. This increase in metabolic rate and consequential heat production is known as adaptive thermogenesis. 


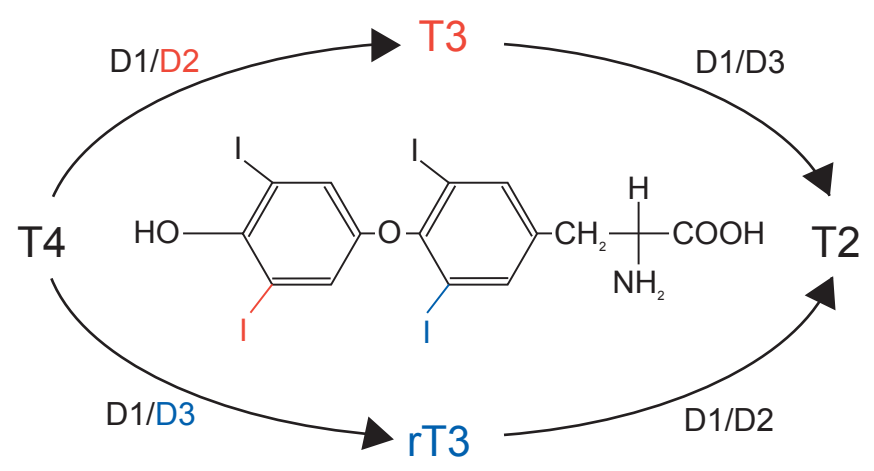

Fig. 2. Thyroid hormone metabolism. Deiodinase enzymes activate and inactivate thyroid hormone by targeted removal of iodine from inner and outer ring of precursor T4. Type 1 deiodinase (D1) can act on both inner and outer ring and gives rise to active T3 as well as inactive rT3 and T2. Type 2 deiodinase (D2) catalyzes outer ring deiodination mainly providing activated $\mathrm{T} 3$ from $\mathrm{T} 4$ but also inactive T2 from rT3. Inner ring deiodination is catalyzed by type 3 deiodinase (D3) resulting in inactivation of $\mathrm{T} 3$ to $\mathrm{T} 2$ or conversion of T4 to rT3.

Thyroid hormone contributes to both obligatory and adaptive thermogenesis [9]. Many studies have pointed towards thyroid hormones as major regulators of mitochondrial function and biogenesis in vivo. In hypothyroid animals mitochondrial gene expression is reduced and can be increased by thyroid hormone administration [10], which acts on transcription of respiratory enzymes. One of the most prominent effects of thyroid hormones on mitochondria is their influence on uncoupling proteins (UCP) [11]. Members of the UCP family (UCP1, $\mathrm{UCP} 2, \mathrm{UCP} 3$ ) are responsible for uncoupling fuel oxidation from ATP synthesis in the inner mitochondrial membrane to generate heat. The proteins are widely expressed in different tissues such as deep white abdominal adipose tissue, abdominal organs and muscles as well as in brown adipose tissue in rodents where they also play a crucial role in restoring normothermia after torpor in hibernating species [12]. Thyroid hormone directly stimulates the transcription of UCP genes acting via thyroid hormone receptor binding sites upstream in the 5' flanking region of the gene. Thyroid hormone up-regulates UCP3 in skeletal muscle and heart and increases Krebs cycle fluxes without affecting ATP synthesis, suggesting that UCP3 might be a main factor in the regulation of resting metabolic rate by thyroid hormone, but this is still a matter of contention $[13,14]$.

\section{Thyroid Hormone Production and Transport}

In a healthy individual or animal, thyroid hormone concentration in plasma is maintained at a relatively stable level. This is due to a finely tuned regulatory feedback system linking thyrotrophin releasing hormone (TRH) synthesis and release in the paraventricular nucleus $(\mathrm{PVN})$ of the hypothalamus to the stimulation of thyroid stimulating hormone (TSH) synthesis and release by the pituitary and in turn to the synthesis and release of thyroxine (T4) by the thyroid gland (fig. 1). Small perturbations in peripheral thyroid hormone concentrations feed back to the PVN to initiate a compensatory increase or decrease in TRH synthesis [15] maintaining tight control over T4 and T3 levels.

The predominant bioactive form of thyroid hormone is T3, which is derived from T4 by the action of deiodinase enzymes. Although global plasma levels of T3 remain fairly constant, localised changes in $\mathrm{T} 3$ concentration are possible and occur through local regulation of deiodinase enzymes. Three deiodinase enzymes exist, each with different roles, and these may be determined by their sub-cellular localisation (fig. 2). Using flag tagged enzymes, Baqui et al. [16] located type 1 deiodinase (D1) at the plasma membrane in transiently transfected HEK293 cells. Although an enzyme with both outer and inner ring deiodination activities which can give rise to both activated (T3) or inactivated (rT3) forms of thyroid hormone from precursor $\mathrm{T} 4$, the cellular location of $\mathrm{D} 1$ in peripheral tissues suggests that a major function is to contribute to the T3 levels in the plasma [16].

Type 2 deiodinase (D2) catalyses outer ring deiodination [17] and is located in the endoplasmic reticulum [16] a favourable location for accessing the nuclear compartment and providing T3 for thyroid hormone receptor activation. Consequently, localised increases in D2 expression can increase the amount of $\mathrm{T} 3$ in specific cells and provide cell-specific regulation of gene transcription by $\mathrm{T} 3$.

Type 3 deiodinase (D3) catalyses inner ring deiodination, resulting in inactivation of T3 to T2 or conversion of T4 to rT3. D3 is located at the plasma membrane, acting to prevent entry of T4 for subsequent conversion or to catabolise active T3 to reduce activation of thyroid hormone receptors [18].

Deiodinases as well as the thyroid hormone receptors are located intracellularly. Therefore, the action and metabolism of thyroid hormones require transport across cell membranes via specific transporters $[19,20]$. Uptake of thyroid hormones by the central nervous system involves at least two types of transporters that can carry both $\mathrm{T} 3$ and $\mathrm{T} 4$. The principal route of T4 entry into the brain is via the blood-brain barrier [21]. Two transporters that are highly specific for thyroid hormones, organic anion transporting polypeptide 1c1 (OATP1C1) and monocarboxylate transporter 8 (MCT8), have been identified $[22,23]$. Immunocytochemical localisation studies show OATP1C1 to be present in capillary endothelial cells in the brain where it is likely to shuttle thyroid hormones across the blood-brain barrier and to a lesser extent through the bloodCSF barrier [22]. MCT8, has a greater affinity and transport rate for T3 [24] and is the dominant carrier protein for thyroid hormone in regions of the brain such as the choroid plexus [25]. It is thus more likely to facilitate the transport of T4 and T3 across the blood-CSF barrier. MCT8 co-localises with the neuronal marker NeuN indicating that it is involved in the cel- 
lular uptake of T3 by target neurons [25, 26]. In view of this critical function, mutations to the MCT8 sequence are likely to have major physiological and behavioural consequences. In support of this, a number of mutations to the human MCT8 sequence are thought to cause of Allan-Herndon-Dudley syndrome [27], associated with severe forms of psychomotor retardation and imbalanced serum thyroid hormone levels. Interestingly, however, the MCT8-null mouse, which has similar abnormal serum T3 and T4 levels, the former being increased to $205 \%$, the latter being reduced to $60 \%$, does not exhibit major neurological defects. This may be because OATP1C1, or hitherto unknown transporters, can compensate for the decreased T3 uptake to the CNS in these mice, as T4 uptake is unaltered and local T3 formation due to increased D2 and decreased D3 activity seems to largely compensate for this deficiency [28]. It remains to be established whether this interpretation is correct.

Taken together, it would seem that thyroid hormone accessibility to the brain is mainly achieved by transport of $\mathrm{T} 4$ via OATP1C1 and T3 via MCT8. Uptake and storage of T4 by tanycytes or astrocytes provides a local source of substrate for D2, expressed in tanycytes, to convert into T3 when required. Active T3 then enters target neurons via MCT8 membrane transporters [25] where T3 actions are mediated by thyroid hormone receptors.

\section{Hypothalamic Distribution of Thyroid Hormone Receptors}

Once transported into neurons, T3 can interact with one of three functional thyroid hormone receptors belonging to the $\alpha$ or $\beta$ receptor sub-groups (TR $\alpha$ or $\operatorname{TR} \beta$ ). Two separate genes, TR $\alpha$ and TR $\beta$, encode 7 identified receptors. Through alternative splicing, three isoforms of $\operatorname{TR} \alpha(\mathrm{TR} \alpha 1, \mathrm{TR} \alpha 2$ and $\mathrm{TR} \alpha 3)$ and four of TR $\beta$ (TR $\beta 1, T R \beta 2)$ and recently discovered TR $\beta 3$ and TR $\beta \Delta 3$ ) are generated [26]. Whereas three isoforms of TR $\beta$ have T3 binding capacity, only TR $\alpha 1$ is able to bind T3 $[27,28]$. Once bound by T3, heterodimers can form with the retinoid $\mathrm{X}$ receptor ( $\mathrm{RXR}$ ), leading to TR binding to T3-responsive elements in promoter regions of thyroid hormoneresponsive genes. A T3-liganded receptor can then induce upregulation of target genes with a positive thyroid hormone response element or down-regulate genes with a negative response element [29]. Unliganded thyroid hormone receptors act as aporeceptors that produce the opposing transcriptional effect, an effect that may be exerted via pre-existing protein complexes interacting with the transcriptional machinery [28]. Several studies using either in situ hybridization or immunocytochemsitry have demonstrated widespread distribution of thyroid hormone receptor isoforms in the hypothalamus of several species, including humans [30-34]. These approaches highlight possible differences between foetal and adult expression patterns and a potential dis-coordination between mRNA expression and the presence of protein for TR $\beta 2[30,33,35]$.
Nevertheless, thyroid hormone receptors are widely distributed, including expression of the most significant isoforms in the arcuate nucleus (ARC) and PVN (table 1). Consistent with the regulatory feedback mechanism for setting the circulating concentrations of thyroid hormone, all functional isoforms of the receptors have been shown to co-localise with TRH in neurons of the PVN [36], providing a possible link between circulating levels of T4/T3 and regulatory feedback control on TRH expression in this nucleus.

In the brain, thyroid hormone is likely to have many roles given the wide distribution of its transporters and receptors. Undoubtedly it plays a key role in the development of the brain as either thyroid hormone deficiency or excess leads to developmental abnormalities. Deficiency results in abnormal neuronal migration, dendritic extensions and myelination [37-41], which leads to severe neurological problems. In excess, as illustrated in the knockout of type III deiodinase, T3 may cause developmental abnormalities in the brain as well as in the pituitary and thyroid gland [42], and these findings may underpin the consequences of $\mathrm{T} 3$ excess during development on thyroid function and body weight in children born to mothers with thyroid hormone resistance or inadequately regulated Grave's disease [43, 44]. In the adult brain, the role of thyroid hormone is less well understood, but one function where thyroid hormone is being recognised to play a role is appetite and energy balance.

\section{Hypothalamic Regulation of Appetite and Energy Balance}

The role of the hypothalamic ARC in appetite and energy balance is well established [45]. Two neuronal populations play pivotal roles in acute regulation of appetite and energy balance; these are the NPY/AgRP neurons and the POMC/ CART neurons. NPY neurons are located in the medial population of ARC neurons adjacent to tanycytes of the third ventricle. NPY has a powerful stimulatory effect on food intake and decreases energy expenditure [46]. Agouti gene-related peptide (AgRP) is co-expressed in the majority of NPY neurons and is another major orexigenic peptide [47, 48]. This peptide acts to block the anorexigenic action of $\alpha$-melanocytestimulating hormone $(\alpha-\mathrm{MSH})$, a principal product of pro-opiomelanocortin (POMC) precursor peptide. POMC neurons comprise a second influential population of neurons of the ARC. Alpha-MSH, a peptide product of the POMC gene, activates the MC4 receptor [49] at locations such as the PVN, to inhibit food intake $[50,51]$. Cocaine-amphetamine-regulated transcript (CART) is a peptide co-expressed with POMC in a majority of POMC neurons and has been demonstrated to have an anorexigenic effect [52]. However, its precise role in appetite and energy balance remains to be firmly established [53].

Transgenic mice expressing fluorescent proteins marking NPY and POMC neurons, coupled with electrophysiological ap- 
Table 1. Distribution of thyroid hormone receptors in hypothalamic region

$\begin{array}{llll}\mathrm{TR} \alpha 1 & \mathrm{TR} \alpha 2 & \mathrm{TR} \beta 1 & \mathrm{TR} \beta 2\end{array}$

Rodent hypothalamus ${ }^{a}$

Suprachiasmatic nucleus

Supraoptic nucleus

Paraventricular nucleus

Ventromedial nucleus

Arcuate nucleus

Lateral hypothalamus

Premammillary region

$\begin{array}{lll}+ & + & \text { ND } \\ + & + & \text { ND } \\ + & + & + \\ + & + & \text { ND } \\ + & + & + \\ \text { ND } & \text { ND } & \text { ND } \\ \text { ND } & \text { ND } & +\end{array}$

Human hypothalamus

Infundibular nucleus

Tuberomammillary nucleus

Supraoptic nucleus

Paraventricular nucleus

Nucleus tuberalis

\begin{tabular}{llll}
+ & + & + & + \\
- & + & - & + \\
+ & + & + & + \\
+ & + & + & + \\
- & + & - & + \\
\hline
\end{tabular}

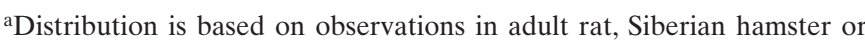
human brain tissue by either immunocytochemistry or in situ hybridization [30-32, 83]. '+' or '-' indicates the receptor protein or mRNA is present or absent. ND indicates there is no information available. In human brain tissue, the infundibular nucleus is the homologous region to the arcuate nucleus of rodents.

proaches, have identified a network of interactions involving neurons of the ARC, PVN and lateral hypothalamus [45, 54]. Such approaches provide evidence for NPY/AgRP neurons with inhibitory synaptic contacts on POMC neurons in the ARC and MC4 receptor-expressing neurons in the PVN. NPY/AgRP neurons receive stimulatory synaptic inputs from orexin-containing neurons in the lateral hypothalamus, whilst POMC neurons provide stimulatory synaptic input to the PVN. Targeted ablation of NPY or POMC neurons in adult mice through the specific transgenic expression of the diphtheria toxin receptor, provides direct evidence for these neurons in appetite and energy balance regulation [55, 56]. A network of fibres from the ARC innervates the PVN-forming synapses with neurons synthesising TRH. All TRH neurons receive inputs from both NPY/AgRP and POMC neurons [57], thus providing a link between sensing of peripheral hormonal signals by the ARC- and TRH-synthesising neurons in the PVN. Consequently, these neurons are important targets for regulation by peripheral hormones communicating the metabolic status of the periphery.

The location of the ARC, proximal to the median eminence (ME) where the blood-brain barrier is non-existent [58], allows direct sensitivity to peripheral satiety or appetite-inducing signals such as leptin, ghrelin, glucocorticoids, insulin and thyroid hormones. Under satiety conditions, circulating leptin plays a key role in regulating ARC activity [59-61]. Synthesised in adipose tissue, leptin may enter the brain via astrocytes in the ARC and ME that have been shown, with the aid of fluorescent tracer dyes, to be accessible from the circulation and to express the leptin receptor as well as NPYY1 receptors [62]. The hormone down-regulates the activity of NPY/AgRP neurons and increases $\alpha$-MSH expression [63, 64], thereby decreasing appetite. During fasting counter-regulatory responses are initiated which include a decrease in leptin levels and an increase in serum corticosteroid and ghrelin concentrations, a process that is associated with increased activity of the orexigenic neurons and decreased activity $\alpha-\mathrm{MSH}$ neurons; hence increasing feeding once food becomes available. Accordingly, as a consequence of food restriction, thyroid hormone levels fall, reducing energy consumption through adaptive thermogenesis in peripheral tissues.

\section{Hypothalamic Thyroid Hormone}

Recently evidence for a more direct involvement of hypothalamic thyroid hormones in the regulation of appetite and energy balance regulation has begun to emerge. The D2 enzyme is expressed in astrocytes of the hypothalamus, yet by far the highest level of expression is found in tanycytes lining the third ventricle. Diano et al. [65] observed that D2 expression and enzyme activity was significantly increased in these tanycytes upon fasting, suggesting that T3 produced by these cells may be involved in the response to acute food shortage. The location of these tanycytes is ideally situated to transmit hormonal signals from the periphery to neurons of the adjacent hypothalamus. Infusion of a D2 inhibitor, iopanoic acid, into the hypothalamic third ventricle of Sprague-Dawley rats prevented a fasting-induced decrease in TRH expression in the PVN, suggesting that D2-containing tanycytes or astrocytes in the ARC locally increase T3 synthesis to facilitate an inhibition of TRH [66]. This in turn would decrease the drive to the pituitary, resulting in lower TSH production and subsequently lower circulating T4 and T3, leading to decreased metabolic rate and thereby conserving energy.

\section{Hormonal Signals Regulating Hypothalamic Thyroid Hormone}

Leptin, a signal of adiposity, was shown to reverse the fastinginduced increase in D2 expression in tanycytes in SpragueDawley rats [67]. Adrenalectomy resulted in the abolition of a fasting-induced increase in corticosterone and prevented the fasting-induced increase of D2 in tanycytes. The fasting response could be re-established by exogenous corticosterone. As leptin administration reduces the fasting-induced rise in corticosterone, the proposed mechanism of leptin action is via a reduction in circulating corticosterone. However, Coppola et al. [67] also observed that leptin reduced D2 activity in rats receiving an exogenous supply of corticosterone. This suggests that although a reduction in corticosterone may be involved in mediating leptin's action, this explanation may not be the 
whole answer. In this circumstance, leptin is unlikely to be mediating its action directly, as tanycytes in adult rats do not express leptin receptors [68]. However, leptin receptors are expressed in astrocytes of the ARC and therefore a possible explanation may be that leptin regulates these astrocytes to affect a leptin-induced decrease of D2 in tanycytes by an indirect mechanism. It is interesting to note however that, although leptin receptors are not found in tanycytes of the adult brain, they are found on these cells during embryonic development and up to at least postnatal day 3, potentially implicating leptin in the development or maturation of the these cells concordant with the maturation of the ARC-PVN projections following a leptin surge at postnatal day 10 [69].

The link between fasting-induced increase of D2 expression in tanycytes and increased expression of NPY in the ARC was revealed recently in a series of experiments by Coppola et al. [70] who also connected the known regulatory role of T3 in UCP expression with the elevation of NPY in the ARC. In this study it was demonstrated using mice expressing GFP in NPY neurons that the end feet of tanycytes expressing D2 make contact with ARC NPY neurons (fig. 1B). T3 administered to hypothyroid mice elevated UCP2 expression in the ARC suggesting that localised $\mathrm{T} 3$ production by $\mathrm{D} 2$ in tanycytes may serve to elevate UCP2 expression. Fasting induced an increase in mitochondrial density, and this effect is abolished in UCP2null mice. A fasting-induced increase in food intake is also suppressed in UCP2-null mice, illustrating the importance of the mitochondrial response to fasting for a manifestation of the hunger response. To add further weight of evidence, D2-null mice have reduced food intake, which could be restored with exogenous T3. Concomitant with this latter response, fasted D2-null mice show no elevation in expression of NPY.

Although tanycytes have been shown to contact gonadotropin-releasing hormone $(\mathrm{GnRH})$ neurons in regions of the ME [71, 72], the tanycyte-NPY neuron interaction is the first report of a specific interaction in the ARC. Interestingly in quail, thyroid hormone functions to alter the interaction between tanycyte end feet and the GnRH neurons to regulate GnRH release [72]. Perhaps there is a parallel in the potential role of leptin and other hormones to alter the plasticity of neuronal interactions in the regulation of hypothalamic circuits involved in appetite and energy balance regulation [54]. It is tempting to speculate that in addition to the regulation of UCP2 expression, thyroid hormone may also regulate either the tanycyte-NPY interaction or the plasticity of other neuronal interactions.

In addition to the ARC, T3 may have a role in the ventromedial nucleus (VMN) in appetite regulation as administration of T3 directly into this hypothalamic nucleus stimulates food intake [73]. The VMN is known to have an inhibitory role in appetite, which may be relayed through a VMN to ARC circuit involving a stimulation of POMC neurons [74]. T3 may therefore serve to inhibit this pathway to increase food intake. TRH administered intracerebroventricularly to the third ven- tricle of rats has been shown to have an anorectic effect [75], suggesting an action of TRH in the brain in regulating food intake. This anorectic action of TRH may at least in part be mediated by the neurotransmitter histamine, as implicated in two studies where i) intracerebroventricular TRH stimulated histamine synthesis in the tuberomammillary nucleus with increased histamine release at the PVN [76] and ii) food intake induced by intracerebroventricular TRH administration is abrogated in histamine $\mathrm{H} 1$ receptor-null mice [77]. This provides evidence that the anorectic effect of TRH, and by implication a reduction in local hypothalamic $\mathrm{T} 3$ levels, may be more complex than first appears and involves tuberomammillary histaminergic regulation.

\section{Relevance of Thyroid Hormone Receptors to Energy Balance}

Thyroid hormone receptors have been demonstrated in the ARC which in turn projects to several hypothalamic areas, including the VMN, dorsomedial nucleus, lateral hypothalamic area and the PVN [63]. The presence of thyroid hormone receptors in this nucleus adjacent to the ependymal layer of the third ventricle in which there is a high level of expression of the transporter MCT8 is ideally placed to be a recipient of T3 transported through this layer and thus influence energy balance mechanisms directly (e.g. NPY expression as highlighted above) or indirectly through networks which incorporate the ARC neurons. However, the presence of thyroid hormone receptors in many of the other hypothalamic nuclei involved in energy balance leaves open the possibility that thyroid hormone may exert a direct influence on more than one aspect of the regulatory mechanisms in appetite and energy balance regulation. Other than co-localisation with TRH in neurons of the PVN, there is a dearth of information regarding the phenotype of thyroid hormone receptor-expressing neurons. One study on human post-mortem hypothalamic tissue, was unable to co-localise thyroid hormone receptors with NPY- and showed only scant localisation with POMC-expressing neurons [32].

The use of mutant mice bearing targeted knockouts of one or both groups of thyroid hormone receptors or mice with specific mutations in a receptor have demonstrated the critical involvement of T3 through thyroid hormone receptor action in energy balance. These include an essential role mediated through actions in the periphery, for example $\mathrm{TR} \alpha$ action in brown adipose tissue on thermogenesis and $\operatorname{TR} \beta$ action in the liver on cholesterol metabolism $[78,79]$. The impact on central mechanisms is demonstrated in a mouse model bearing either a TR $\beta 2$ receptor knockout or a total deletion of both TR $\beta$ isoforms, where these mutations fail to relay the inhibitory feedback control of T3 on TRH expression, but does not affect the leptin-induced suppression [80,81]. TR $\alpha$ involvement in metabolic regulation through actions in the brain is illustrated in a transgenic mouse with TR $\alpha 1$ engineered to have a low affinity for T3 and 
which is essentially an unliganded receptor at physiological circulating T3 concentrations. This mouse is hypermetabolic, shows much reduced fat depots, hyperphagia and resistance to diet-induced obesity. These effects were shown to be reversed by exogenous $\mathrm{T} 3$ administration or crossing mice with a TR $\beta$ null mouse that have elevated serum T3 as a consequence of this mutation. Subsequent metabolic challenges and analysis of gene expression in brown adipose tissue in the TR $\alpha$ mutant mice provided evidence of a central action of the unliganded receptor to increase sympathetic outflow [77]. The site(s) where TR $\alpha$ mediates these effects remains to be determined.

Fasting conditions can occur seasonally for many free-living species, and hypothalamic T3 availability has been shown to be involved in adaptation to reduced food availability [34, 82-85]. Driven by photoperiodic changes and/or an endogenous clock, seasonal mammals often undergo profound physiological changes well in advance of the critical period of the year, as part of an energy-saving strategy. Differential deiodinase regulation and consequently $\mathrm{T} 3$ availability have been demonstrated to be crucial in seasonal physiology of reproduction [82-85] as well as body weight [34]. Induced by decreasing day length, the Siberian hamster (Phodopus sungorus) ceases reproduction and displays a profound reduction in food intake and body weight. An increase in D3 expression in the ependymal layer of the third ventricle and hence a decrease of hypothalamic T3, was shown to be crucial for seasonal changes in both reproductive activity and energy balance. These changes could be blocked by exogenous central T3 release [34]. In addition to the prevention of weight loss, the T3 implants also prevented typical short-day-induced changes in gene expression (P. Barrett et al. unpublished), implying that T3 might act directly on the transcription of genes involved in homeostatic mechanisms. Recently, another member of the thyroid hormone family, 3-iodothyronamine, has been linked to the balance between glucose and lipid [86]. The decarboxylated and deiodinated metabolite of T3 and T4 blocked carbohydrate utilisation, and metabolic pathways were re-routed from carbohydrate to lipid utilisation in response to 3-iodothyronamine. Moreover, it induced hypothermia in Siberian hamsters and mice, suggesting that it might be one of the factors that are necessary for torpor, a controlled decrease of body temperature that occurs seasonally and/or in times of energy shortage.

\section{The Thyroid Hormone as a Potential Target of Energy Balance Manipulation}

Thyroid hormones are an important component in appetite regulation and energy balance, in the periphery as well as in central structures. Acute metabolic challenges and photoperiodic manipulation of long-term energy requirements demonstrate a role for hypothalamic thyroid hormone in both shortterm and long-term regulation of energy balance mechanisms. Thyroid hormone regulation of mitochondrial functions, particularly regulation of uncoupling proteins, may be the common link between regulation of metabolism in peripheral tissues and sensing of energy deficit by homeostatic regulatory mechanisms in the hypothalamus. In this new role for thyroid hormone in the hypothalamus, tanycytes of the ependymal layer surrounding the third ventricle assume a new level of importance. Although the thyroid hormone system seems an obvious target for pharmaceutical interventions to manipulate energy balance mechanisms in the quest to reduce adiposity, the ubiquitous expression of thyroid hormone receptors negates this as a practical approach to alter energy balance. However, tanycyte function regulating T4 transport or conversion may prove to be an accessible target in the future.

Animal models have provided the foundation for progress toward our understanding of the role of thyroid hormone in the hypothalamus. So how relevant will this be to the human situation? Recent studies in humans would indicate that animal models will be relevant as the components of thyroid systems show similar distribution in either tanycytes (D2 and MCT8), thyroid hormone receptors (wide hypothalamic distribution) and the presence of D3 and MCT8 in neurons [32].

Other products of thyroid hormone metabolism have yet to be explored in depth in relation to mechanism of energy balance, but it seems likely that there are many more facets to discover about this system that may be exploitable to regulate appetite and energy balance.

\section{Acknowledgements}

This work was supported by the Scottish Government Rural and Environment Research Analysis Directorate, and the European Commission FP6 (LSHM-CT-2003-503041).

\section{References}

1 Tata JR, Ernster L, Suranyi EM: Interaction between thyroid hormones and cellular constituents. I. Binding to isolated sub-cellular particles and subparticulate fractions. Biochim Biophys Acta 1962; 60:461-479.

2 Tata JR: Inhibition of the biological action of thyroid hormones by actinomycin D and puromycin Nature 1963;197:1167-1168.
3 Krotkiewski M: Thyroid hormones in the pathogenesis and treatment of obesity. Eur J Pharmacol 2002;440:85-98.

4 Brunova J, Bruna J, Joubert G, Koning M: Weight gain in patients after therapy for hyperthyroidism. S Afr Med J 2003;93:529-531.

5 Dale J, Daykin J, Holder R, Sheppard MC, Franklyn JA: Weight gain following treatment of hyperthyroidism. Clin Endocrinol 2001;55:233-239.
6 Lechan RM, Fekete C: The TRH neuron: a hypothalamic integrator of energy metabolism. Prog Brain Res 2006;153:209-235.

7 Silva JE: Thermogenic mechanisms and their hormonal regulation. Physiol Rev 2006;86:435-464.

8 Bianco AC, Maia AL, da Silva WS, Christoffolete MA: Adaptive activation of thyroid hormone and energy expenditure. Biosci Rep 2005;25:191-208. 
9 Silva JE: The thermogenic effect of thyroid hormone and its clinical implications. Ann Intern Med 2003;139:205-213.

10 Scheller K, Sekeris CE: The effects of steroid hormones on the transcription of genes encoding enzymes of oxidative phosphorylation. Exp Physiol 2003;88:129-140.

11 Lanni A, Moreno M, Lombardi A, Goglia F: Thyroid hormone and uncoupling proteins. FEBS Lett 2003;543:5-10.

12 Liu XT, Lin QS, Li QF, Huang CX, Sun RY: Uncoupling protein mRNA, mitochondrial GTP-binding, and T4 5'-deiodinase activity of brown adipose tissue in Daurian ground squirrel during hibernation and arousal. Comp Biochem Physiol A Mol Integr Physiol 1998;120:745-752.

13 Boss O, Samec S, Paoloni-Giacobino A, Rossier C, Dulloo A, Seydoux J, Muzzin P, Giacobino JP: Uncoupling protein-3: a new member of the mitochondrial carrier family with tissue-specific expression. FEBS Lett 1997;408:39-42.

14 Bézaire V, Seifert EL, Harper ME: Uncoupling protein-3: clues in an ongoing mitochondrial mystery. FASEB J 2007;21:312-324.

15 Fekete C, Lechan RM: Negative feedback regulation of hypophysiotropic thyrotropin-releasing hormone (TRH) synthesizing neurons: role of neuronal afferents and type 2 deiodinase. Front Neuroendocrinol 2007;28:97-114.

16 Baqui MM, Gereben B, Harney JW, Larsen PR, Bianco AC: Distinct subcellular localization of transiently expressed types 1 and 2 iodothyronine deiodinases as determined by immunofluorescence confocal microscopy. Endocrinology 2000;141: 4309-4312.

17 Bianco AC, Salvatore D, Gereben B, Berry MJ, Larsen PR: Biochemistry, cellular and molecular biology, and physiological roles of the iodothyronine selenodeiodinases. Endocrine Rev 2002;23:38-89.

18 Baqui M, Botero D, Gereben B, Curcio C Harney JW, Salvatore D, Sorimachi K, Larsen PR, Bianco AC: Human type 3 iodothyronine selenodeiodinase is located in the plasma membrane and undergoes rapid internalization to endosomes. J Biol Chem 10;278:1206-1211.

19 Hennemann G, Docter R, Friesema EC, de Jong M, Krenning EP, Visser TJ: Plasma membrane transport of thyroid hormones and its role in thyroid hormone metabolism and bioavailability. Endocr Rev 2001;22:451-476.

20 Friesema EC, Jansen J, Milici C, Visser TJ: Thyroid hormone transporters. Vitam Horm 2005;70:137167.

21 Dratman MB, Crutchfield FL, Schoenhoff MB: Transport of iodothyronines from bloodstream to brain: contributions by blood:brain and choroid plexus:cerebrospinal fluid barriers. Brain Res 1991; 554:229-236.

22 Sugiyama D, Kusuhara H, Taniguchi H, Ishikawa S, Nozaki Y, Aburatani H, Sugiyama Y: Functional characterization of rat brain-specific organic anion transporter (Oatp14) at the blood-brain barrier: high affinity transporter for thyroxine. J Biol Chem 2003 31;278:43489-43495.

23 Friesema EC, Ganguly S, Abdalla A, Manning Fox JE, Halestrap AP, Visser TJ: Identification of monocarboxylate transporter 8 as a specific thyroid hormone transporter. J Biol Chem 2003;278:4012840135 .

24 Friesema EC, Kuiper GG, Jansen J, Visser TJ, Kester MH: Thyroid hormone transport by the human monocarboxylate transporter 8 and its ratelimiting role in intracellular metabolism. Mol Endocrinol 2006;20:2761-2772.
25 Heuer H, Maier MK, Iden S, Mittag J, Friesema EC, Visser TJ, Bauer K: The monocarboxylate transporter 8 linked to human psychomotor retardation is highly expressed in thyroid hormone-sensitive neuron populations. Endocrinology 2005;146:17011706.

26 Harvey CB, Bassett JH, Maruvada P, Yen PM, Williams GR: The rat thyroid hormone receptor (TR) Deltabeta3 displays cell-, TR isoform-, and thyroid hormone response element-specific actions. Endocrinology 2007;148:1764-1773.

27 Williams GR: Cloning and characterization of two novel thyroid hormone receptor beta isoforms. Mol Cell Biol 2000;20:8329-8342.

28 Lazar MA: Thyroid hormone receptors: multiple forms, multiple possibilities. Endocr Rev 1993;14: 184-193.

$29 \mathrm{Wu}$ Y, Koenig RJ: Gene regulation by thyroid hormone. Trends Endocrinol Metab 2000;11:207-211.

30 Bradley DJ, Young WS 3rd, Weinberger C: Differential expression of $\alpha$ and $\alpha$ thyroid hormone receptor genes in rat brain and pituitary. Proc Natl Acad Sci U S A 1989; 86:7250-7254.

31 Lechan RM, Qi Y, Berrodin TJ, Davis KD, Schwartz HL, Strait KA, Oppenheimer JH, Lazar MA: Immunocytochemical delineation of thyroid hormone receptor beta 2-like immunoreactivity in the rat central nervous system. Endocrinology 1993; 132:2461-2469.

32 Alkemade A, Vuijst CL, Unmehopa UA, Bakker O, Vennström B, Wiersinga WM, Swaab DF, Fliers E: Thyroid hormone receptor expression in the human hypothalamus and anterior pituitary. J Clin Endocrinol Metab 2005;90:904-912.

33 Bradley DJ, Towle HC, Young WS 3rd: Spatial and temporal expression of alpha- and beta-thyroid hormone receptor mRNAs, including the beta 2-subtype, in the developing mammalian nervous system J Neurosci 1992;12:2288-2302.

34 Barrett P, Ebling FJ, Schuhler S, Wilson D, Ross AW, Warner A, Jethwa P, Boelen A, Visser TJ, Ozanne DM, Archer ZA, Mercer JG, Morgan PJ: Hypothalamic thyroid hormone catabolism acts as a gatekeeper for the seasonal control of body weight and reproduction. Endocrinology 2007;148: 3608-3617.

35 Cook CB, Kakucska I, Lechan RM, Koenig RJ: Expression of thyroid hormone receptor beta 2 in rat hypothalamus. Endocrinology 1992;130:1077-1079.

36 Lechan RM, Qi Y, Jackson IM, Mahdavi V:. Identification of thyroid hormone receptor isoforms in thyrotropin-releasing hormone neurons of the hypothalamic paraventricular nucleus. Endocrinology 1994;135:92-100.

37 Jansen J, Friesema EC, Milici C, Visser TJ: Thyroid hormone transporters in health and disease. Thyroid 2005; 15:757-768.

38 Schwartz CE, Stevenson RE: The MCT8 thyroid hormone transporter and Allan-Herndon-Dudley syndrome. Best Pract Res Clin Endocrinol Metab 2007;21:307-321.

39 Trajkovic M, Visser TJ, Mittag J, Horn S, Lukas J, Darras VM, Raivich G, Bauer K, Heuer H: Abnormal thyroid hormone metabolism in mice lacking the monocarboxylate transporter 8 . J Clin Invest 2007;117:627-635.

40 Bernal J: Thyroid hormones and brain development. Vitam Horm 2005;71:95-122.

41 Anderson GW, Schoonover CM, Jones SA: Control of thyroid hormone action in the developing rat brain. Thyroid 2003;13:1039-1056.

42 Hernandez A, Martinez ME, Fiering S, Galton VA, St Germain D: Type 3 deiodinase is critical for the maturation and function of the thyroid axis. J Clin Invest 2006;116:476-84.
43 Woeber KA: Triiodothyronine production in Graves' hyperthyroidism. Thyroid 2006;16:687-690.

44 LaFranchi S: Thyroid hormone in hypopituitarism, Graves' disease, congenital hypothyroidism, and maternal thyroid disease during pregnancy. Growth Horm IGF Res 2006;16(suppl A):20-24.

45 Abizaid A, Gao Q, Horvath TL: Thoughts for food: brain mechanisms and peripheral energy balance. Neuron 2006 21;51:691-702.

46 Clark JT, Kalra PS, Kalra SP: Neuropeptide Y stimulates feeding but inhibits sexual behavior in rats. Endocrinology 1985;117:2435-2442.

47 Ollmann MM, Wilson BD, Yang YK, Kerns JA, Chen Y, Gantz I, Barsh GS: Antagonism of central melanocortin receptors in vitro and in vivo by agouti-related protein. Science 1997;278:135-138.

48 Rossi M, Kim MS, Morgan DG, Small CJ, Edwards CM, Sunter D, Abusnana S, Goldstone AP, Russell SH, Stanley SA, Smith DM, Yagaloff K, Ghatei MA, Bloom SR: A C-terminal fragment of Agoutirelated protein increases feeding and antagonizes the effect of alpha-melanocyte stimulating hormone in vivo. Endocrinology 1998;139:4428-4431.

49 Fan W, Boston BA, Kesterson RA, Hruby VJ, Cone $\mathrm{RD}$ : Role of melanocortinergic neurons in feeding and the agouti obesity syndrome. Nature 1997;385: 165-168.

50 Kim MS, Rossi M, Abusnana S, Sunter D, Morgan DG, Small CJ, Edwards CM, Heath MM, Stanley SA, Seal LJ, Bhatti JR, Smith DM, Ghatei MA, Bloom SR: Hypothalamic localization of the feeding effect of agouti-related peptide and alphamelanocyte-stimulating hormone. Diabetes 2000; 49:177-182.

51 Wirth MM, Olszewski PK, Yu C, Levine AS, Giraudo SQ: Paraventricular hypothalamic alphamelanocyte-stimulating hormone and MTII reduce feeding without causing aversive effects. Peptides 2001;22:129-134.

52 Kristensen P, Judge ME, Thim L, Ribel U, Christjansen KN, Wulff BS, Clausen JT, Jensen PB, Madsen OD, Vrang N, Larsen PJ, Hastrup S: Hypothalamic CART is a new anorectic peptide regulated by leptin. Nature 1998;393:72-76.

53 Abbott CR, Rossi M, Wren AM, Murphy KG, Kennedy AR, Stanley SA, Zollner AN, Morgan DG, Morgan I, Ghatei MA, Small CJ, Bloom SR: Evidence of an orexigenic role for cocaine- and amphetamine-regulated transcript after administration into discrete hypothalamic nuclei. Endocrinology 2001;142:3457-3463.

54 Horvath TL: The hardship of obesity: a soft-wired hypothalamus. Nat Neurosci 2005;8:561-565.

55 Gropp E, Shanabrough M, Borok E, Xu AW, Janoschek R, Buch T, Plum L, Balthasar N, Hampel B, Waisman A, Barsh GS, Horvath TL, Brüning JC: Agouti-related peptide-expressing neurons are mandatory for feeding. Nat Neurosci 2005;8:12891291.

56 Luquet S, Perez FA, Hnasko TS Palmiter RD: NPY/AgRP neurons are essential for feeding in adult mice but can be ablated in neonates. Science 200528;310:683-685.

57 Fekete C, Légrádi G, Mihály E, Huang QH, Tatro JB, Rand WM, Emerson CH, Lechan RM: Alphamelanocyte-stimulating hormone is contained in nerve terminals innervating thyrotropin-releasing hormone-synthesizing neurons in the hypothalamic paraventricular nucleus and prevents fasting-induced suppression of prothyrotropin-releasing hormone gene expression. J Neurosci 2000;20:1550 1558 . 
58 Peruzzo B, Pastor FE, Blázquez JL, Schöbitz K, Peláez B, Amat P, Rodríguez EM: A second look at the barriers of the medial basal hypothalamus. Exp Brain Res 2000;132:10-26.

59 Campfield LA, Smith FJ, Guisez Y, Devos R, Burn $\mathrm{P}$ : Recombinant mouse OB protein: evidence for a peripheral signal linking adiposity and central neural networks. Science 1995;269:546-549.

-60 Pelleymounter MA, Cullen MJ, Baker MB, Hecht R, Winters D, Boone T, Collins F: Effects of the obese gene product on body weight regulation in ob/ob mice. Science 1995;269:540-543.

61 Halaas JL, Gajiwala KS, Maffei M, Cohen SL, Chai BT, Rabinowitz D, Lallone RL, Burley SK, Friedman JM: Weight-reducing effects of the plasma protein encoded by the obese gene. Science 1995; 269:543-546.

62 Cheunsuang O, Morris R: Astrocytes in the arcuate nucleus and median eminence that take up a fluorescent dye from the circulation express leptin receptors and neuropeptide Y Y1 receptors. Glia 2005;52:228-233.

63 Schwartz MW, Woods SC, Porte D Jr, Seeley RJ, Baskin DG: Central nervous system control of food intake. Nature 2000;404:661-671.

64 Zigman JM, Elmquist JK: Minireview: From anorexia to obesity - the yin and yang of body weight control. Endocrinology 2003;144:3749-3756.

65 Diano S, Naftolin F, Goglia F, Horvath TL: Fastinginduced increase in type II iodothyronine deiodinase activity and messenger ribonucleic acid levels is not reversed by thyroxine in the rat hypothalamus. Endocrinology 1998;139:2879-2884.

66 Coppola A, Hughes J, Esposito E, Schiavo L, Meli R, Diano S: Suppression of hypothalamic deiodinase type II activity blunts TRH mRNA decline during fasting. FEBS Lett 2005;579:4654-4658.

67 Coppola A, Meli R, Diano S: Inverse shift in circulating corticosterone and leptin levels elevates hypothalamic deiodinase type 2 in fasted rats. Endocrinology 2005;146:2827-2833.

68 Carlo AS, Meyerhof W, Williams LM: Early developmental expression of leptin receptor gene and [125I]leptin binding in the rat forebrain. J Chem Neuroanat 2007;33:155-163.
69 Ahima RS, Prabakaran D, Flier JS: Postnatal leptin surge and regulation of circadian rhythm of leptin by feeding. Implications for energy homeostasis and neuroendocrine function. J Clin Invest 1998; 101:1020-1027.

70 Coppola A, Liu ZW, Andrews ZB, Paradis E, Roy MC, Friedman JM, Ricquier D, Richard D, Horvath TL, Gao XB, Diano S: A central thermogenic-like mechanism in feeding regulation: an interplay between arcuate nucleus T3 and UCP2. Cell Metab 2007;5:21-33.

71 Kozlowski GP, Coates PW: Ependymoneuronal specializations between LHRH fibers and cells of the cerebroventricular system. Cell Tissue Res 1985;242:301-311.

72 Yamamura T, Yasuo S, Hirunagi K, Ebihara S, Yoshimura T: T(3) implantation mimics photoperiodically reduced encasement of nerve terminals by glial processes in the median eminence of Japanese quail. Cell Tissue Res 2006;324:175-179.

73 Kong WM, Martin NM, Smith KL, Gardiner JV, Connoley IP, Stephens DA, Dhillo WS, Ghatei MA, Small CJ, Bloom SR: Triiodothyronine stimulates food intake via the hypothalamic ventromedial nucleus independent of changes in energy expenditure. Endocrinology 2004;145:5252-5258.

74 Sternson SM, Shepherd GM, Friedman JM: Topographic mapping of VMH $\rightarrow$ arcuate nucleus microcircuits and their reorganization by fasting. Nat Neurosci 2005;8:1356-1363.

75 Suzuki T, Kohno H, Sakurada T, Tadano T, Kisara $\mathrm{K}$ : Intracranial injection of thyrotropin releasing hormone (TRH) suppresses starvation-induced feeding and drinking in rats. Pharmacol Biochem Behav 1982;17:249-253.

76 Gotoh K, Fukagawa K, Fukagawa T, Noguchi H, Kakuma T, Sakata T, Yoshimatsu H: Hypothalamic neuronal histamine mediates the thyrotropin-releasing hormone-induced suppression of food intake. J Neurochem 2007;103:1102-1110.

77 Sjogren M, Alkemade A, Mittag J, Nordstrom K, Katz A, Rozell B, Westerblad H, Arner A, Vennstrom B: Hypermetabolism in mice caused by the central action of an unliganded thyroid hormone receptor alpha1. EMBO J 2007;26:4535-4545.

78 Gullberg H, Rudling M, Saltó C, Forrest D, Angelin B, Vennström B: Requirement for thyroid hormone receptor beta in $\mathrm{T} 3$ regulation of cholesterol metabolism in mice. Mol Endocrinol 2002;16:17671777.
79 Marrif H, Schifman A, Stepanyan Z, Gillis MA, Calderone A, Weiss RE, Samarut J, Silva JE: Temperature homeostasis in transgenic mice lacking thyroid hormone receptor-alpha gene products. Endocrinology 2005;146:2872-2884.

80 Abel ED, Ahima RS, Boers ME, Elmquist JK, Wondisford FE: Critical role for thyroid hormone receptor beta2 in the regulation of paraventricular thyrotropin-releasing hormone neurons. J Clin Invest 2001;107:1017-1023.

81 Dupré SM, Guissouma H, Flamant F, Seugnet I, Scanlan TS, Baxter JD, Samarut J, Demeneix BA, Becker N: Both thyroid hormone receptor (TR) beta 1 and TR beta 2 isoforms contribute to the regulation of hypothalamic thyrotropin-releasing hormone. Endocrinology 2004;145:2337-2345.

82 Viguie C, Battaglia DF, Krasa HB, Thrun LA, Karsch FJ: Thyroid hormones act primarily within the brain to promote the seasonal inhibition of luteinizing hormone secretion in the ewe. Endocrinology 1999;140:1111-1117.

83 Yoshimura T, Yasuo S, Watanabe M, Iigo M, Yamamura T, Hirunagi K, Ebihara S: Light-induced hormone conversion of $\mathrm{T} 4$ to $\mathrm{T} 3$ regulates photoperiodic response of gonads in birds. Nature 2003;426: $178-181$.

84 Watanabe M, Yasuo S, Watanabe T, Yamamura T, Nakao N, Ebihara S, Yoshimura T: Photoperiodic regulation of type 2 deiodinase gene in Djungarian hamster: possible homologies between avian and mammalian photoperiodic regulation of reproduction. Endocrinology 2004;145:1546-1549.

85 Watanabe T, Yamamura T, Watanabe M, Yasuo S, Nakao N, Dawson A, Ebihara S, Yoshimura T: Hypothalamic expression of thyroid hormone-activating and -inactivating enzyme genes in relation to photorefractoriness in birds and mammals. Am J Physiol Regul Integr Comp Physiol 2007;292: R568-R572.

86 Braulke LJ, Klingenspor M, Debarber A, Tobias SC, Grandy DK, Scanlan TS, Heldmaier G: 3Iodothyronamine: a novel hormone controlling the balance between glucose and lipid utilisation. J Comp Physiol [B] 2008;178:167-177. 